\title{
Effects of pruning on growth and yield of cucumber (Cucumis sativus) Mercy variety in The acid soil of North Kalimantan, Indonesia
}

\author{
MARDHIANA, ANKARDIANSYAH PANDU PRADANA, MUH. ADIWENA ${ }^{\vee}$, KARTINA, DWI SANTOSO, \\ RIZZA WIJAYA, ANAS MALIKI \\ Faculty of Agriculture, Universitas Borneo Tarakan. Jl. Amal Lama No. 1, Tarakan 77123, North Kalimantan, Indonesia. `email: \\ muhammadadiwena@gmail.com
}

Manuscript received: 31 May 2017. Revision accepted: 19 June 2017.

\begin{abstract}
Mardhiana, Pradana AP, Adiwena M, Kartina, Santoso D, Wijaya R, Maliki A. 2017. Effects of pruning on growth and yield of cucumber (Cucumis sativus) Mercy variety in The acid soil of North Kalimantan, Indonesia. Cell Biol Dev 1: 13-17. In recent years, cucumber production in Tarakan, North Kalimantan, only reached 20 tons ha ${ }^{-1}$; cucumber production potential could reach 49 tons ha ${ }^{-1}$. Several factors that limit the low productivity of cucumbers in Tarakan are acid soil and cultivation techniques which are still limited. This study aimed to determine the effect of pruning on the growth and yield of cucumbers in acid soil in Tarakan. The study was conducted using Randomized Complete Block Design with the treatment without pruning (P0), prunings of the shoots on the main stem (P1), pruning of whole lateral branches above the third section (P2), and pruning of 2 lateral branches that emerged first above the third section (P4). The results showed that plant height was $16.17 \%(\mathrm{P} 1)$ and $2.26 \%(\mathrm{P} 2)$, also lower $0.13 \%$ higher (P3) than the control (P0). The highest number of leaves was found in treatment P1 (16.19\%) compared to P0. The best fruit diameter was also found in the P1 treatment, with a $4.93 \%$ difference compared to the P0. Furthermore, a highly significant and the best result on weight per fruit were also obtained by P1 treatment. The results showed that the fruit weight of the P1 treatment $(11.39 \%)$ was higher than the P0. This study provided new information that the pruning treatment of shoots on the main stem of cucumber variety Mercy in acid soil could increase the diameter and weight of cucumber.
\end{abstract}

Keywords: Fruit diameter, lateral branches, leaves, low $\mathrm{pH}$, main stem

\section{INTRODUCTION}

Cucumber (Cucumis sativus L.) is one of the vegetable crops from the Cucurbitaceae family commonly planted by farmers in Indonesia. Cucumber cultivation is widespread worldwide, both in tropical and subtropical areas Cucumber plants in Indonesia are grown in lowlands to highlands. The central regions of the cucumber cultivation area in Indonesia are West Java, East Java, Central Java, Aceh, and Bengkulu. DNA sequencing found that melon and cucumber are of Asian origin and have numerous previously overlooked species-level relatives in Australia and around the Indian Ocean (Sebastian et al. 2010).

Cucumber production in Indonesia is still relatively low. Based on data from the Central Bureau of Statistics, cucumber production in Indonesia continues to decline yearly. From 2011 to 2015 , the cucumber productions were 521,535 tons, 511,525 tons, 491,636 tons, 477,989 tons, and 447,696 tons, respectively. Besides genetic factors, environmental factors such as climate, cultural practices, and post-harvest conditions affect plant performance (Crawley 2009). Therefore, the proper cultivation techniques as a cultural practice must be done in Indonesia to increase cucumber production.

Increasing cucumber production requires appropriate cultivation techniques. One possible action to increase cucumber production is improving cultivation techniques through proper pruning. According to Usenik et al. (2008), pruning influenced vegetative growth and fruit quality and had no negative effect on peach. However, cucumber plants of age 21 Days After Planting (DAP) usually grow with very dense branches and leaves, leading to vegetative growth, so the formed flowers and fruits tend to decrease.

Some cucumber farmers in Tarakan City have not done intensive cultivation techniques such as pruning, which can affect plants. According to Beadle et al. (2007), pruning in Acacia trees can decrease the total number of branches and improve stem straightness. With few branches, the plant will get an optimized light availability. Light affects plant developmental processes (Feng et al. 2008). However, the application of the pruning technique is still few due to the limited knowledge and poor information obtained by farmers

Cucumber cultivation needs to be developed appropriately and sustainably. Therefore, pruning is needed to increase the growth and yield of cucumbers. Therefore, the pruning treatment experiment is expected to increase the growth and yield of cucumbers. Therefore, this study aimed to determine the effect of pruning on the growth and yield of cucumber variety Mercy in acid soils in Tarakan, North Kalimantan, Indonesia. 


\section{MATERIALS AND METHODS}

\section{Time and site of study}

The study was conducted in Experimental Farm of Faculty of Agriculture, Universitas Borneo Tarakan, Tarakan, North Kalimantan, Indonesia, from December 2016 to February 2017.

\section{Experimental design}

The study was conducted using Randomized Complete Block Design with the treatment without pruning (P0), the shoot of prunings on the main stem (P1), pruning of whole lateral branches above the third section (P2), and pruning of two lateral branches that emerged first above the third section (P3). These treatments were replicated five times so that there were 20 units of the experimental unit. Each experimental unit consists of four plant samples, so the total sample is 80 .

\section{Cultural practice}

The study area was measured and cleared from weeds and other plants grown. The land was dug with a depth of \pm $20 \mathrm{~cm}$ using a hoe. The planting process was done using a dough tool with a depth of $3-5 \mathrm{~cm}$ at a distance of $60 \mathrm{~cm}$ between the rows and $30 \mathrm{~cm}$ within the rows. Two seeds are inserted into the planting hole, then covered with a little soil. Routine watering was done every morning, especially in the early growth phase at 7-14 DAP. Watering was done every two days when the cucumber flowers emerged and were not done when it rains. Stitching was done when the plant was at the age of 14 DAP by replacing the plant that died or grew abnormally with new plants, and thinning was done by leaving one best plant per planting hole at the plant age of 21 DAP. Application of stake was made when cucumber was planted at the age of a week after planting. This study used bamboo or wood as a stoke marker for each plant and connected each other with ropes.

Basic fertilization used manure with a fertilizer dose of 20 tons ha ${ }^{-1}$ (429 g plant $\left.^{-1}\right)$. Further fertilization was done at the planting time and when the plants were 10 days after planting. The fertilizers applied were urea $280 \mathrm{~kg} \mathrm{ha}^{-1}(6 \mathrm{~g}$ plant $\left.^{-1}\right)$, SP-36 $260 \mathrm{~kg} \mathrm{ha}^{-1}\left(5 \mathrm{~g} \mathrm{plant}^{-1}\right)$ and $\mathrm{KCl} 525 \mathrm{~kg} \mathrm{ha}^{-1}$ (9.5 $\left.\mathrm{g} \mathrm{plant}^{-1}\right)$. The half dose was applied at the planting time and when the plants were at 10 DAP. Fertilizer was inserted into the soil at a distance of $\pm 15 \mathrm{~cm}$ from the stem. The cucumber fruits that were ready to be harvested followed the criteria: the fruit was green, and the diameter was more than $2.5 \mathrm{~cm}$. Cucumbers were harvested until the productive harvest was complete. Harvesting was done at 47, 48, and 49 DAP.

\section{Pruning}

Pruning of maintenance was done by removing leaves and branches that grow before the third section. Treatment of cucumber pruning was done under the applied treatment. Pruning was done when the plant was 33 DAP using pruning shears to obtain good results.

\section{Data analysis}

Data of observation results were analyzed using Variance Analysis ( $F$ test) to determine the treatment's effect. If a significantly different result was found, the Least Significance Different (LSD) test with a 95\% confidence level was conducted.

\section{RESULTS AND DISCUSSION}

Based on the analysis of variance, there is an effect of pruning in cucumbers. The pruning highly affects the plant length, number of leaves, fruit diameter and weight, and flowering age. However, the pruning did not affect the fruit length or the number of fruits per plant. The recapitulation of the effects of pruning on the growth and yield of cucumber is described in Table 1.

Based on the result of the variance, it is known that the pruning treatment has a very significant effect on the cucumber length at 50 DAP (Figure 1). For example, figure 1 showed the treatment of pruning of two lateral branches that emerged first above the third section (P3) showed the highest yield compared to other treatments of $272.45 \mathrm{~cm}$, but not significantly different from the treatment of $\mathrm{P} 0$ and $\mathrm{P} 2$. On the other hand, treatment of shoot pruning on the main stem (P1) significantly resulted in a shorter plant than other treatments with no shoot pruning, but visually it was seen that the branch was longer than that without pruning.

Treatment of shoot pruning on the main stem (P1) resulted in the highest number of leaves per plant (59.90 pieces) compared to other treatments. In addition, treatment of shoot pruning on the main stem could increase the number of leaves by $16.19 \%$ compared to that without pruning (P0). The number of cucumber leaves due to the effect of pruning in detail is shown in Figure 2.

Based on the 5\% LSD test, it is known that the shoot pruning treatment on the main stem (P1) and the pruning of the two lateral branches that emerged first above the third section (P3) yielded the fastest flowering time rate compared to other treatments, which is 38 DAP. Pruning treatments (P1, P2, and P3) can generally accelerate the flowering times rather than without pruning treatment $(\mathrm{P} 0)$. $\mathrm{P} 1$ and P3 could shorten the flowering time by $2.93 \%$ compared to without pruning treatment $(\mathrm{P} 0)$. The average flowering age of cucumbers due to pruning in detail is shown in Figure 3.

The result of variance analysis showed that all cucumber pruning treatments had no significant effect on fruit length and the number of fruit per plant (Table 2). Based on the results, the average fruit length was $19.98 \mathrm{~cm}$, and the average number of fruit that is harvestable in each sample was 3.11 pieces. The data in several fruit parameters is the harvestable fruit data. All treatments were suspected of producing optimal assimilates, so they were insufficient to increase the number of harvestable fruit. 
Table 1. Recapitulation of the results of the effects of pruning on the growth and yield of cucumbers

\begin{tabular}{lc}
\hline Parameters & F test result \\
\hline Plant length & $* *$ \\
Number of leaves & $* *$ \\
Flowering age & $*$ \\
Fruit length & $\mathrm{ns}$ \\
Fruit diameter & $* *$ \\
Number of fruit per plant & $\mathrm{ns}$ \\
Fruit weight & $* *$ \\
\hline
\end{tabular}

Note: $\mathrm{ns}=$ not significantly different; $*$ = significantly different ** = highly significantly different

Table 2. Effect of pruning on fruit length and number of fruit per plant

\begin{tabular}{lcc}
\hline Treatment & Fruit length (cm) & $\begin{array}{c}\text { Number of fruit } \\
\text { per plant }\end{array}$ \\
\hline P0 & $19.68 \mathrm{~ns}$ & $3.15 \mathrm{~ns}$ \\
P1 & $20.05 \mathrm{~ns}$ & $3.00 \mathrm{~ns}$ \\
P2 & $20.20 \mathrm{~ns}$ & $3.20 \mathrm{~ns}$ \\
P3 & $19.99 \mathrm{~ns}$ & $3.10 \mathrm{~ns}$ \\
Average & 19.98 & 3.11 \\
\hline
\end{tabular}

Note: ns= not significantly different; P0: treatment of without pruning ( $\mathrm{P} 0)$, the shoot of prunings on the main stem (P1), pruning of whole lateral branches above the third section (P2), and pruning of 2 lateral branches that emerged first above the third section (P3).

The result of the statistical test showed that the pruning treatment had a significant effect on fruit diameter. The general pruning treatment $(\mathrm{P} 1, \mathrm{P} 2$, and $\mathrm{P} 3)$ increased the fruit diameter compared to the treatment without pruning (P0). The effect of pruning on average fruit diameter in detail is shown in Figure 4.

The highest average fruit diameter was obtained by the pruning treatment of shoots on the main stem (P1) of 4.26 $\mathrm{cm}$. The shoot that was prunings on the main stem increased the fruit diameter percentage by $4.92 \%$ compared to the treatment without pruning. The addition of fruit diameter is closely related to the number of leaves. Therefore, the optimal leaf surface area can produce assimilate, increasing the fruit diameter.

The result of the statistical test showed that the pruning treatment had a significant effect on the production per plant. For example, treatment of shoot pruning on the main stem (P1) yielded the highest average weight per fruit of $427.11 \mathrm{~g}$ plant $^{-1}$ compared to other treatments (P0, P2, and P3). The effect of pruning on weight per fruit is shown in Figure 5.

In general, pruning treatments $(\mathrm{P} 1, \mathrm{P} 2$, and $\mathrm{P} 3)$ had a better effect on average weight per fruit than those without pruning (P0). However, the best result was obtained by the P1 treatment, which showed an increase of $11.38 \%$ compared to without pruning treatment (P0).

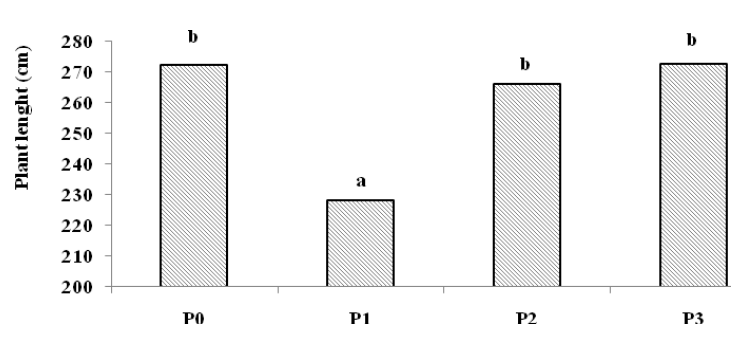

Figure 1. Effect of pruning on plant length

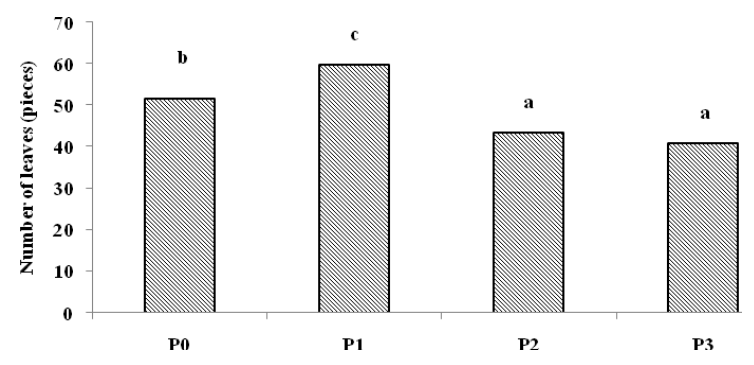

Figure 2. Effect of pruning on number of leaves

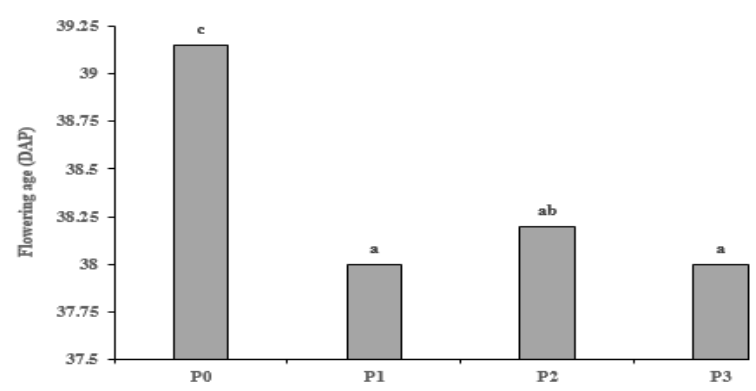

Figure 3. Effect of pruning on flowering age

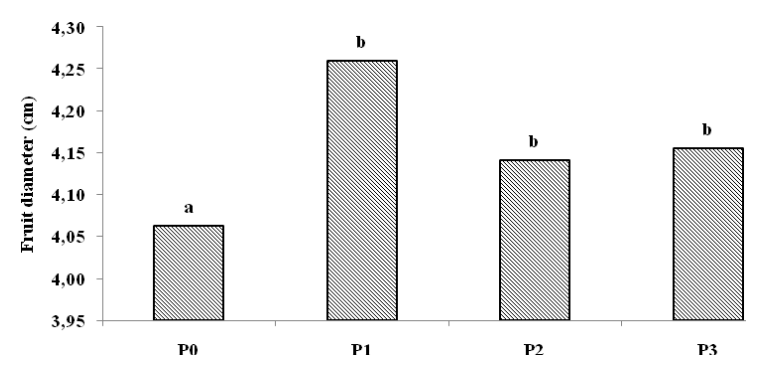

Figure 4. Effect of pruning on fruit diameter

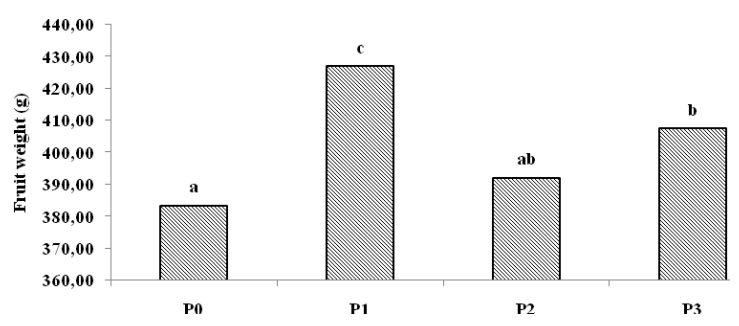

Figure 5. Effect of pruning on fruit weight. 


\section{Discussion}

The plants pruned on the main stem are shorter than other treatments. It might be related to the flow of auxin in the plants; the synthesis of auxin on the shoot of the main stem is stopped due to the shoot pruning, while the synthesis of cytokinin increases and further affects the branch growth. Ghosh et al. (2011) said that pruning suppresses apical dominance. The apical meristem and the young leaves are the centers of TAA and IAA (Indole Acetic Acid) synthesis, which are then transported to the stems, thus inhibiting the development of lateral shoots. IAA is one type of auxin that causes apical dominance. Therefore, IAA triggers change in plant development (Vanneste and Friml 2009).

The production data proved that the cucumber length was not positively correlated with the yield. The plant stems are not a major contributor to photosynthesis, but it is more affected by the number of leaves. The optimal number of leaves is the largest contributor to photosynthesis because the leaf is a plant organ with stomata associated with photosynthesis ( $\mathrm{Xu}$ and Zhou 2008). Fischer et al. (2012) said that increasing the leaffruit ratio generally increases fruit growth and carbohydrate content.

Pruning is intended to control the optimal number of leaves, thereby improving the yield. Pruning is an attempt to create a better state of the plant, so that sunlight can enter the whole parts of the plant, increase interception of light into the canopy of plants and increase the availability of air circulation and $\mathrm{CO} 2$ in the canopy. The sufficient light and $\mathrm{CO} 2$, and other supporting factors will increase the photosynthesis rate, leading to the availability of photosynthesis. However, the excessive vegetative growth caused a suboptimal use of photosynthesis results and decreased yield production (Coggins Jr and Lovatt. 2014).

The shoots of pruning on the main stem might inhibit the production of auxin in the main stem and increase the cytokinin hormone. That affects the extension of the lateral branches; the longer lateral branches produce a larger number of sections, as the increasing number of sections will also increase the number of leaves. Meier and Leuschner (2008) said that leaf expansion and stand leaf area of beech are controlled by several abiotic factors, including spring temperature and possibly nitrogen supply. Nitrogen affects photosynthesis and photoprotection in leaves (Pompelli et al. 2010), and the results of these photosynthates, which plants will use to support an increase in yields (Hibberd et al. 2010).

The production of auxin in the main stem continues to proceed without the shoot of prunings, which is certainly not expected by farmers because it will make an apical dominance that results in a longer vegetative phase and inhibition of the flowering time of the plant. That was in line with Dun et al. (2009) statement that the production of auxin might trigger the production of a second hormone to inhibit bud outgrowth.

The shoot of pruning on the main stem (P1) is expected to create an optimal growing space for the leaves, which perform photosynthesis. The result of the photosynthesis is allocated for cell enlargement in the fruit tissue since the meristematic cells in the fruit will increase the volume size so that the cell growth is in line with the increase of fruit diameter. Pruning essentially reduces unproductive parts of the plant, so assimilating the photosynthesis process is more widely allocated to enhance other plant growth processes, such as cell enlargement. Photosynthate positively affects fruit as a photosynthesis result (Yu et al., 2013).

Cucumber pruning can produce a better fruit weight. It is proven by the fruit weight produced by a shoot of pruning on the main stem (P1), which can gain a weigher fruit in the cucumber Mercy variety between 350-400 g per fruit. Although the average fruit weight shows an improvement, it has not been able to achieve the average yield of the cucumber Mercy variety. Based on the data, the cucumber Mercy variety can produce $3.5-5 \mathrm{~kg}_{\text {plant }}^{-1}$, while this study only reached $1.28 \mathrm{~kg}$. That might be caused by the cucumber being harvested only 3 times because, after the 3 rd harvest time, the plant suffered a pest attack of fruit fly (Bactrocera sp.), causing rotten cucumber fruit and not feasible to harvest. This study provided new information that shooting prunings on the main stem could increase cucumber Mercy variety's quantity (fruit weight) in acid soils in Tarakan, North Kalimantan.

\section{REFERENCES}

Beadle C, Barry K, Hardiyanto E, Irianto R, Mohammed C, Rimbawanto A. 2007. Effect of pruning Acacia mangium on growth, form and heart rot. For Ecol Manage 238(1): 261-267.

Benner BL. 1988. Effects of apex removal and nutrient supplementation on branching and seed production in Thlaspi arvense (Brassicaceae). Am J Bot 75(5): 645-651.

Coggins Jr CW, Lovatt CJ. 2014. Plant Growth Regulators. In: Ferguson L, Grafton-Cardwell EE (eds) Citrus Production Manual. UC ANR, California.

Crawley MJ. 2009. Life history and environment. In: Crawley MJ (eds) Plant Ecology, Second Edition. Wiley-Blackwell, Victoria.

Dun EA, Brewer PB, Beveridge CA. 2009. Strigolactones: discovery of the elusive shoot branching hormone. Trends in Plant Sci 14(7): 364372 .

Farquhar GD, Sharkey TD. 1982. Stomatal conductance and photosynthesis. Ann Rev Plant Physiol 33(1): 317-345.

Feng S, Martinez C, Gusmaroli G, Wang Y, Zhou J, Wang F,Chen L, Yu L, Iglesias-Pedraz JM, Kircher S, Schäfer E, Fu X, Fan LM, Deng XW. 2008. Coordinated regulation of Arabidopsis thaliana development by light and gibberellins. Nature 451(7177): 475-479.

Fischer G, Almanza-Merchán PJ, Ramírez F. 2012. Source-sink relationships in fruit species: A review. Revista Colombiana de Ciencias Hortícolas 6(2): 238-253.

Ghosh A, Chikara J, Chaudhary D. 2011. Diminution of economic yield as affected by pruning and chemical manipulation of Jatropha curcas L. Biomass and Bioenergy 35(3): 1021-1029.

Hansen P. 1967. 14C-studies on apple trees. I. The effect of the fruit on the translocation and distribution of photosynthatess. Physiologia Plantarum 20(2): 382-391

Hibberd JM, Sheehy JE, Langdale JA. 2008. Using C 4 photosynthesis to increase the yield of rice-rationale and feasibility. Cur Opin Plant Biol 11(2): 228-231.

Meier IC, Leuschner C. 2008. Leaf size and leaf area index in Fagus sylvatica forests: competing effects of precipitation, temperature, and nitrogen availability. Ecosystems 11(5): 655-669.

Pompelli MF, Martins SC, Antunes WC, Chaves AR, DaMatta FM. 2010. Photosynthesis and photoprotection in coffee leaves is affected by nitrogen and light availabilities in winter conditions. J Plant Physiol 167(13): 1052-1060. 
Sebastian P, Schaefe H, Telford IR, Renner SS. 2010. Cucumber (Cucumis sativus) and melon (C. melo) have numerous wild relatives in Asia and Australia, and the sister species of melon is from Australia. Proc Nat Acad Sci USA 107(32): 14269-14273.

Usenik V, Solar A, Meolic D, Stampar F. 2008. Effects of summer pruning on vegetative growth, fruit quality and carbohydrates of 'Regina' and 'Kordia' sweet cherry trees on 'Gisela 5'. Europ J Hort Sci 73 (2): $62-68$.
Vanneste S, Friml J. 2009. Auxin: a trigger for change in plant development. Cell 136(6): 1005-1016.

Xu Z, Zhou G. 2008. Responses of leaf stomatal density to water status and its relationship with photosynthesis in a grass. J Exp Bot 59(12): 3317-3325.

Yu K, Fan Q, Wang Y, Wei J, Ma Q, Yu D, Li J. 2013. Function of leafy sepals in Paris polyphylla: photosynthate allocation and partitioning to the fruit and rhizome. Funct Plant Biol 40(4): 393-399. 